\title{
THE "ONE-AND-A-HALF" SYNDROME
}

\author{
CASE REPORT
}

PÉRICLES MARANHÃO-FILHO*, HELIOF. LOPES **, MAURICE B. VINCENT***

ABSTRACT - The authors describe a case of a ten-year-old boy with one-and-a-half syndrome secondary to a lesion at the dorsal tegmentum in the lower pons, and comment on the horizontal gaze physiology.

KEY-WORDS: one-and-a-half syndrome, pons tegmentum, horizontal eye movements.

\section{Síndrome "one-and-a-halP": relato de caso}

RESUMO - Os autores descrevem o caso de um menino de dez anos de idade com síndrome "one-and-a-half" secundária a lesāo no tegmento dorsal da porção inferior da ponte e comentam aspectos acerca da fisiologia da motilidade ocular conjugada horizontal.

PALAVRAS-CHAVE: síndrome "one-and-a-half", tegmento pontino, movimento ocular horizontal.

The "one -and-a-half" syndrome ${ }^{9}$ (OAHS) is an ocular movement disorder characterized by lateral gaze palsy to one direction associated with internuclear ophthalmoplegia (INO) to the opposite direction. In the present report a ten-year-old boy suffering from OAHS caused by a lesion at the dorsal tegmentum in the lower pons is described. Anatomical and pathophysiological aspects of this relatively rare syndrome are discussed.

\section{CASE REPORT}

RAP, a ten-year-old black boy, was apparently healthy until August 1995 when his mother noticed an abnormal cephalic posture. His head tended to bend towards the left side. One month later she observed that his mouth was deviated to the right and his left eye could not close completely. There was no history of headache, seizures, vertigo, vomiting, disgeusia, hipoacusia, blurred vision or diplopia. He was otherwise healthy and had had a normal childhood. His six brothers, father and mother were also normal. The general physical examination was unremarkable. On the neurological examination the head was tilted to the left side, and there was a left peripheral-type facial palsy with Bell's sign. Ocular examination disclosed paralysis of the left horizontal gaze. Horizontal gaze to opposite direction showed weakness of the adducting eye and monocular nystagmus of the abducting eye (Fig 1). There were no ptosis, exotropia or esotropia. Pursuit movements were preserved both upwards and downwards. The pupils were $3 \mathrm{~mm}$ in diameter, and reactive to light. Convergence was preserved and the other cranial nerves were normal. An MR scan showed a T1-weighted (T1W) hypointensity area at the dorsal lower tegmentum of the pons with contrast enhancement (Fig 2). A spinal tap showed CSF with 15 cells/

Department of Neurosurgery, National Cancer Institute (INCa), Rio de Janeiro, Brazil: * Neurologist : ** Neurosurgeon. Department of Neurology, Federal University of Rio de Janeiro (HUCFF/UFRJ), Brazil: ***Neurologist. Aceite: 19-junho-1996.

Dr. Péricles Maranhão Filho - Av. Canal de Marapendi 1680 apto 1802 - 22631-050 Rio de Janeiro RJ - Brasil. Fax 55.21 4395594. E-mail: pericles@ uninet.com.br 


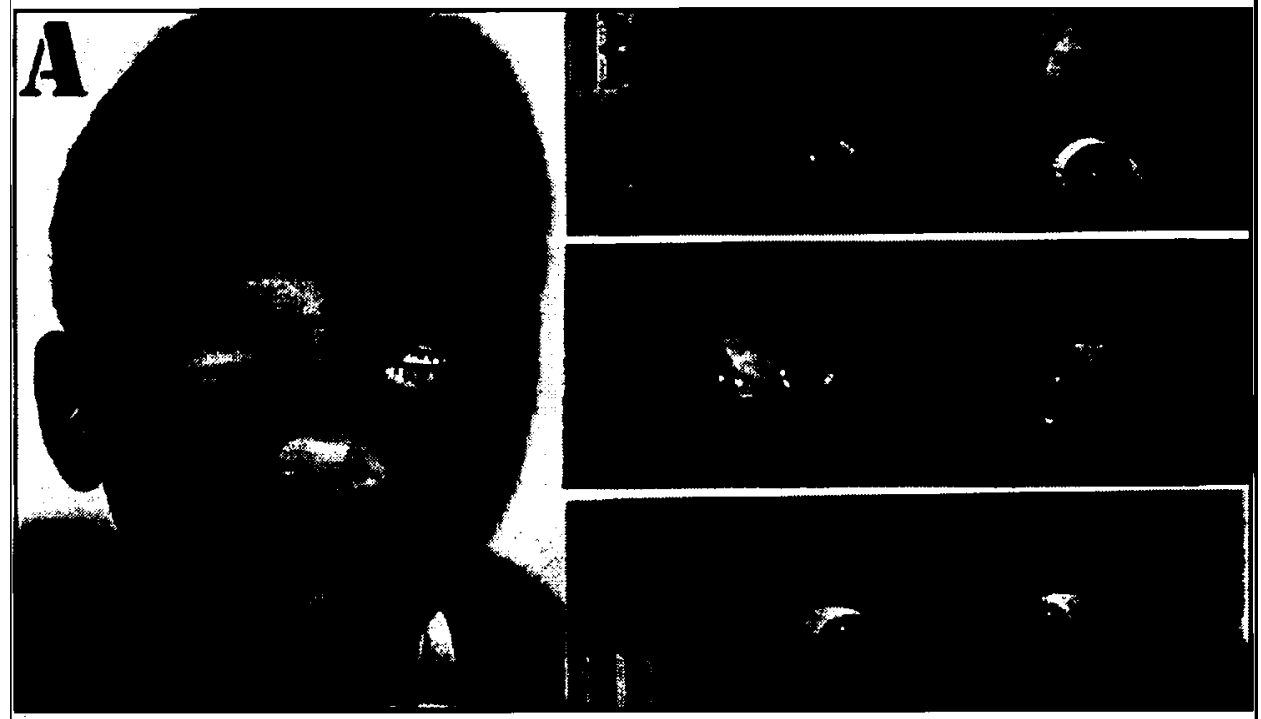

Fig 1. (A) Left peripheral-type facial palsy. (B) Left conjugate gaze palsy. (C) Right conjugate gaze with adduction paresis. (D) intact convergence.

$\mathrm{mm} 3$ including some red cells due to a tap bleeding, their morphology was normal and there was no malignant cell; the total protein was $46 \mathrm{mg} / \mathrm{dL}$.

The patient was operated upon, and a strawyellow bulge lesion with micro vessels located $15 \mathrm{~mm}$ upper from the obex and measuring $15 \times 10 \mathrm{~mm}$, in the left paramedian tegmentum of the pons was removed. The clinical picture was unchanged following surgery. Pathological examination revealed an inespecific glial reaction with perivascular inflammatory infiltration without malignancy. Six months after surgery there was just left peripheral facial palsy and ocular gaze palsy to the same side.

\section{DISCUSSION}

In 1967, Miller Fisher ${ }^{9}$ described a syndrome he termed "one-and-a-half-syndrome" (OAHS) consisting of a "conjugate lateral gaze palsy in one direction, plus one half of a gaze palsy in the other". Many aetiologies of OAHS have been described ${ }^{1.2}$ mostly vascular, but also demyelinating and neoplasic disorders. The syndrome usually results from a single, unilateral and relatively small lesion at the dorsal tegmentum of the lower pons. Occasionally an ocular paralysis occurs, one eye looking ahead without any horizontal movement and the other staying abducted. The latter eye does not move beyond the midline when horizontal movements are tested. Vertical eye movements are relatively preserved.
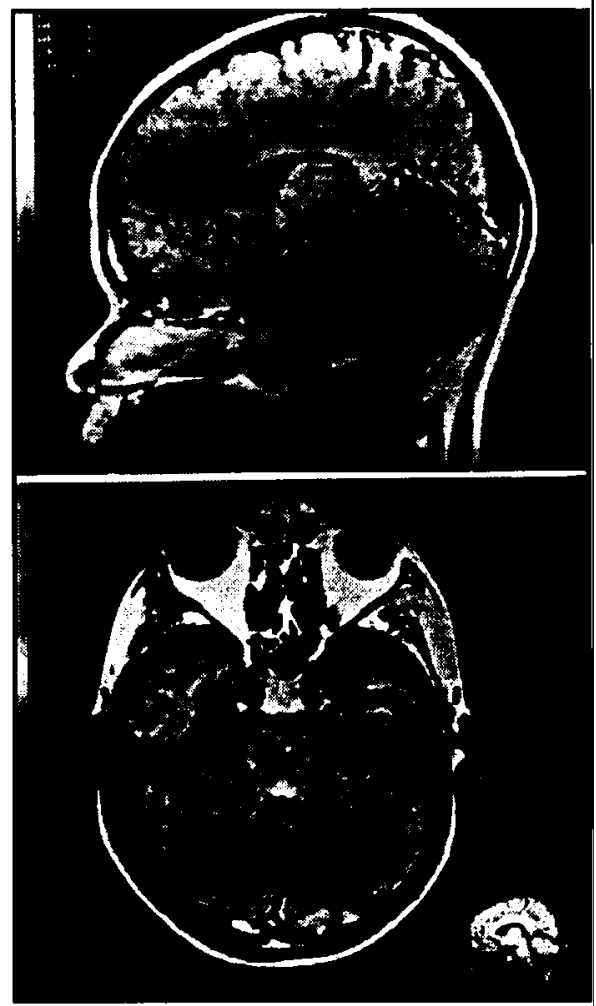

Fig 2. RMITIW with gadolinium. Slice longitudinal $(A)$ and transversal $(B)$ high density lesion in the dorsal pons tegmentum (arrows). 
In OAHS the abducens nucleus (AN) and/or the paramedian pontine reticular formation (PPRF) located rostrally and ventrally to that nucleus are damaged, producing an ipsilateral conjugate gaze palsy. Damage to the ipsilateral medial longitudinal fasciculus (MLF), which lies at the same level or just above the AN, accounts for the unilateral internuclear ophthalmoplegia (INO) ${ }^{14}$. In addition, during the acute phase, exotropia of the contralateral eye, no deviation, or less commonly, esotropia of the eye ipsilateral to the lesion secondary to the paresis of the sixth nerve, may be seen in primary position of gaze.

Wall and Wray ${ }^{16}$ reviewed 29 reported cases of OAHS and added more 20 patients of their own, with age varying from 16 to 78 years. Curiously, in 12 out of 20 patients the lesion was on the right side. The present patient had a deficit of horizontal gaze to the left side combined with a paresis of adduction to the opposite direction.

In this syndrome, the normal vertical eye movements and convergence suggest that motor fibers and nuclei of the third cranial nerves were preserved. The degree and duration of the horizontal gaze impairment caused by unilateral lesions in the brain above the level of the oculomotor nucleus may vary according to the size and location of the lesion. The more cerebral tissue is damaged, the more prolonged is the defect in spontaneous contralateral conjugate gaze $e^{4}$.

There seems to be four possible damage locations for the OAHS lateral gaze palsy: at both the AN and the PPRF, only at the AN, only at the PPRF, and at both AN root fibres together with the contralateral MLF, in case of two distinct lesions $\mathrm{s}^{4,14,16}$.

The abducens nucleus (AN): extensive experimental data from cats and monkeys ${ }^{3 A, 14}$ suggest that the AN contains two types of cells, i.e., motoneurons which innervate the ipsilateral external rectus muscle (magnocellular motor neurons) and excitatory internuclear neurons that decussate at the level of the nucleus, ascend in the contralateral MLF and terminate at the medial rectus subdivision of the oculomotor nuclear complex. These internuclear neurons are required for any type of horizontal movement, since adduction (except for convergence) is suppressed in complete forms of internuclear ophthalmoplegia ${ }^{14}$.

Selective damage of the AN produces ipsilateral gaze palsy for all lateral eye movements, including reflex movements. Peripheral facial palsy without gustatory defict is a common associated sign in AN lesions ${ }^{16}$ because the genu of the facial nerve wraps around the AN and the gustatory fibers are carried in the intermediate branch of the seventh nerve to the nucleus solitarius of the medulla.

The paramedian pontine reticular formation (PPRF): numerous experimental studies in monkeys have produced data supporting the importance of the PPRF for integration of horizontal conjugate gaze $e^{4,6,8,10,12}$. Electrical stimulation of the PPRF induces ipsilateral ocular deviation while stereotaxic lesions provoke ipsilateral gaze palsies ${ }^{14,16}$. Smaller lesions ( 1 to $2 \mathrm{~mm}$ ) in the tegmentum of the pons, specifically in the PPRF, induce paralysis of ipsilateral conjugate gaze for as long as one year. Outside the pons the amount of tissue destruction necessary to affect horizontal gaze is much greater than in PPRF lesions ${ }^{10}$.

The PPRF contains two main types of neurons associated with eye movements, the phasic and the tonic cells. The former (excitatory burst neurons) are active during saccades, namely all kinds of rapid eye movements (voluntary saccades and quick phases of nystagmus). The latter (tonic neurons) are active during fixation and during slow eye movements, mainly smooth pursuit and the slow phases of nystagmus ${ }^{14}$. In addition, there are inhibitory burst neurons located to the medial reticular formation, caudal to the AN that travelling through the giganto-cellular tegmental field, crossing the brain-stem and terminating in the contralateral AN; and pause neurons, rostral to the AN that discharge tonically and pause, presumably exerting a normal inhibitory influence on saccadic burst neurons during periods of fixation ${ }^{16}$. 
The PPRF is connected to the ipsilateral AN by an excitatory pathway, probably involving a relay close to the nucleus itself. The PPRF acts as the final supranuclear centre for lateral movement, either voluntary or pursuit. Only the oculocephalic movement partly escapes its control, because certain vestibular tracts project directly to the vestibular nuclei ${ }^{14}$.

Internuclear ophthalmoplegia (INO): the INO is characterized by paresis or paralysis of the ipsilateral eye adduction - on attempted horizontal gaze to the contralateral side - and horizontal jerk nystagmus in the contralateral abducting eye. Typically convergence is preserved if the lesion does not extend to the mesencephalon. Bilateral lesions cause bilateral defects in adduction and nystagmus in the abducting eye. In addition there are nystagmus on upward gaze, as well as bilateral partial ptosis. Lesions of the MLF do not cause paralysis of conjugate horizontal or vertical gaze 7 . Upgaze palsy, downgaze palsy, complete vertical gaze palsy and vertical saccade for both upward and downward gaze have been known to be related to bilateral lesions involving the rostral interstitial nucleus of medial longitudinal fasciculus (RiMLF) cell group and the posterior commissure, ${ }^{913}$. Gordon and Bender" described rare forms of visual symptoms due to lesions of the MLF such as monocular diplopia, oscillopsia and diplopia with oscillopsia of only one of two images, usually the false, while the true image remains stationary.

Paralytic pontine exotropia (PPE): the presence of exotropia in OAHS was first observed by Fisher ${ }^{9}$. In the acute phase, the exotropic eye shows abduction nystagmus during attempts to move it further laterally, and there is extreme slowness of adduction when the eye moved to the midline. The other eye remains straight ahead, unable to move right or left. PPE is attributed to an acute brainstem lesion involving the PPRF and the MLF on the side opposite the deviated eye ${ }^{15,16}$. Again, normal midbrain ocular motor functions are shown by intact vertical gaze, convergence, and puppillary constrictor reflex activity.

In conclusion, the semiological diagnosis of the OAHS is comparatively simple and allows great anatomical precision. Peripheral facial palsy without gustatory deficit is a common associated sign and eventually the most exuberant symptom.

\section{REFERENCES}

1. André C, Castro ALZ, Vincent MB, Mattos JP, Maranhăo-Fïlho PA, Novis SAP. Síndrome "one-and-a-half": consideraçס̄es anatomoclínicas a proposito de un caso. Arq Neuropsiquiatr 1989;47:365-370.

2. Azevedo D Jr. Pontine tegmentum hematoma: a case report with the "one-and-a-half"syndrome without pyramidal tract deficit. Arq Neuropsiquiatr 1995;53:475-480.

3. Baker R, Highstein SM. Physiological identification of interneurons and motoneurons in the abducens nucleus. Brain Res 1975;91:292-298.

4. Bender MB. Brain control of conjugate horizontal and vertical eye movements: a survey of the structural and functional correlates. Brain 1980;103:23-69.

5. Bogousslavsky J, Meienberg O. Eye-movement disorders in brain-stem and cerebellar stroke. Arch Neurol 1987;44:141-148.

6. Buttner U, Fuhry L. Eye movements. Curn Opin Neurol 1995;8:77-82.

7. Christoff N, Anderson PJ, Nathanson M, Bender MB. Problems in anatomic analysis of lesions of the median longitudinal fasciculus. Arch Neurol 1960;2:293-304.

8. Cohen B, Komatsuzakj A, Bender MB. Eletrooculographic syndrome in monkeys after pontine reticular formation lesions. Arch Neurol 1968:18:78-92.

9. Fisher CM. Some neuro-ophthalmological observations. J. Neurol Neurosurg Psychiatry 1967;30:383-392.

10. Goebel HH, Komatsuzaki A, Bender MB, Cohen B. Lesions of the pontine tegmentum and conjugate gaze paralysis. Arch Neurol 1971;24:431-440.

11. Gordon RM, Bender MB. Visual phenomena in lesions of the median longitudinal fasciculus. Arch Neurol 1966;15:238-240.

12. Keller EL. Participation of medial pontine reticular formation in eye movement generation in monkey. J Neurophysiol 1974:37:316-332.

13. Kim SJ, Kang KJ, Lee AS, Lee MC. Isolated or predominant ocular motor nerve palsy as a manifestation of brain stem stroke. Stroke 1993;24:581-586.

14. Pierrot-Deseilligny CH, Chain F, Serdau M, Gray F, Lhermitte F. The "one-and-a-half" syndrome eletro-oculographic analyses of five cases with deductions about the physiological mechanisms of lateral gaze. Brain 1981;104:665-699.

15. Sharpe JA, Rosenberg MA, Hoyt WF, Daroff RB. Paralytic pontine exotropia: a sign of acute unilateral pontine gaze palsy and internuclear ophthalmoplegia. Neurology 1974;24:1076-1081.

16. Wall M, Wray SH. The one-and-a-half syndrome: a unilateral disorder of the pontine tegmentum: a study of 20 cases and review of the literature. Neurology 1993;33:971-980. 